\title{
No evidence so far for the dissemination of carbapenemase-producing Enterobactericeae in the community in Switzerland
}

\author{
Magdalena Nüesch-Inderbinen, Katrin Zurfluh, Herbert Hächler and Roger Stephan*
}

\begin{abstract}
Background: Carbapenemase-producing Enterobacteriaceae represent an increasing threat to public health and to the treatment of serious nosocomial infections. The aim of this study was to screen for the presence of carbapenemase-producing Enterobacteriaceae in human carriers in community settings in Switzerland, a country representative of central Europe.
\end{abstract}

Findings: Three hundred and fourteen stool samples of healthy staff members of a meat-processing company and 291 fecal swabs from primary care patients were recovered in Switzerland between April 2012 and July 2012 and were tested for carbapenemase-producing Enterobacteriaceae isolates by selecting for growth on a carbapenemcontaining selective medium. Six resulting isolates (5 Escherichia coli and 1 Citrobacter youngae) were subjected to antimicrobial susceptibility tests and PCR analysis by screening for the carbapenemase genes bla $a_{\mathrm{OXA}-48,}$, bla $a_{\mathrm{VIM}}$, bla $a_{\mathrm{NDM}-1}$, and $b a_{\mathrm{KPC}}$ as well as for the extended-spectrum $B$-lactamase genes bla $a_{\mathrm{TEM}}, b / a_{\mathrm{SHV}}, b / a_{\mathrm{CTX}-\mathrm{M}}$ and bla $a_{\mathrm{CMY}-2}$. No carbapenemase genes were detected. Resistance to B-lactam antibiotics was due to carriage of the extended-spectrum $B$-lactamase CTX-M-15 in 4 isolates, to CTX-M-14 in one further isolate and to the plasmidic AmpC-ß-lactamase CMY-2 in one isolate.

Conclusions: These results show that carbapenemase-producing Enterobacteriaceae are as yet not present in the community. Continuous surveillance is necessary to anticipate future trends in the prevalence and dissemination of carbapenem resistant isolates in the population.

Keywords: Carbapenemase, Dissemination, Enterobacteriaceae, Healthy carriers

\section{Findings}

The emergence and worldwide spread of carbapenemase producing Enterobacteriaceae is of great concern to public health services and a major threat to the efficacy of carbapenem antibiotics such as imipenem, ertapenem or meropenem, which are drugs of choice for the treatment of infections due to extended-spectrum ß-lactamase (ESBL)-producing strains [1].

Currently globally disseminating carbapenem hydrolysing ß-lactamases include the Ambler Class A carbapenemase $\mathrm{KPC}$, the Ambler class B metallo-ß-lactamases (MBLs) such as the IMP-, the VIM- or the NDM-type carbapenemases, and the Ambler class D expanded-spectrum

\footnotetext{
* Correspondence: stephanr@fsafety.uzh.ch

National Centre for Enteropathogenic Bacteria and Listeria, Institute for Food Safety and Hygiene, Vetsuisse Faculty University of Zurich,

Winterthurerstrasse 272, 8057 Zurich, Switzerland
}

oxacillinases (OXA-type enzymes) [2,3]. The epidemiology of carbapenemase-producing Enterobacteriaceae, (especially Klebsiella pneumoniae) in European countries follows a pattern typical for hospital-acquired pathogens, and the spread from hospital to community settings is hence a matter of time, as demonstrated in the past by the dissemination of ESBL-producers [4]. Due to the variability of resistance levels to carbapenem antibiotics, carbapenemaseproducers cannot be easily detected. Thus, the actual prevalence in the community remains unknown and possibly even underestimated [3].

The aim of the present study was therefore to screen for the presence of carbapenemase-producing Enterobacteriaceae in human carriers in a non-hospital setting in Switzerland.

Switzerland, a country with a restrictive antibiotic policy [5], lies not only at a geographical center, but also

\section{() Biomed Central}


represents a multicultural socioeconomic and epidemiological intersection in the center of Europe, where differences between linguistic regions reflect the differences observed between surrounding European countries [6]. This makes the country ideal for monitoring temporal-spacial trends in antibiotic resistance in central Europe.

KPC-carbapenemases in $K$. pneumoniae was first reported in a hospital in Switzerland in 2010 [7] attributed to travel-related importation from Italy, followed by four further cases introduced to Switzerland, from hospitalized patients initially treated in Italy and Greece [8]. NDM producing isolates were first reported in Geneva in 2011 [9] and related to travel importation from the Balkans and the Indian subcontinent. In 2012, Oxa-48 producers were identified in Switzerland [10].

Our aim was to determine whether or not, carbapenemase producers have spread beyond the hospital setting.

In an ongoing study of routine stool samples from healthy factory staff and a study on ESBL-producing Enterobacteriaceae in fecal swabs of primary care patients [11], 314 stool samples and 291 fecal swabs were obtained and incubated for 24 hours at $37^{\circ} \mathrm{C}$ in $10 \mathrm{ml}$ of Enterobacteriaceae Enrichment (EE) broth (BD, Franklin Lakes, USA) to enhance the recovery of Enterobacteriaceae. One loopful each of the enrichment cultures was inoculated onto chromogenic Brilliance CRE agar (Oxoid, Hampshire, UK) containing a carbapenem to select for carbapenemase producers. Pink colonies (E. coli) and blue colonies (Klebsiella, Enterobacter, Serratia and Citrobacter spp.) were selected for further analysis. Otherwise pigmented or white colonies were discarded. In total, 6 isolates were collected. Three $E$ coli isolates from the 314 stool samples, one $C$. youngae and 2 E. coli isolates from the 291 fecal swab samples were identified using the API ID 32 E test (bioMérieux, Marcy l'Etoile, France) and screened by PCR for the presence of $b l a_{\mathrm{OXA}-48}, b l a_{\mathrm{VIM}}, b l a_{\mathrm{NDM}-1}$, and $b l a_{\mathrm{KPC}}$, using primers described previously [12,13] and using DNA isolated from strains IMMZH201261080, IMMZH201165843, IMMZH201163819 and IMMZH63372-3 as positive controls, respectively (kindly provided by Dr. Guido Bloemberg, Institute of Medical Microbiology, Zürich). The minimal inhibitory concentration of imipenem for the six isolates was performed using Etest IP strips (bioMérieux, Marcy l'Etoile, France), according to the Clinical and Laboratory Standards Institute [14].

No carbapenemase genes were detected in the analysed isolates. Resistance levels to imipenem remained for all isolates below the susceptibility breakpoint of the new interpretive criteria implemented by the CLSI [14], minimal inhibitory concentrations ranging between $0.125 \mu \mathrm{g} / \mathrm{ml}$ and $0.25 \mu \mathrm{g} / \mathrm{ml}$. Further susceptibility testing performed by disk diffusion assay, using antibiotic disks
(Becton Dickinson and Company, Maryland, USA) revealed an ESBL phenotype for 5 of the 6 isolates and an AmpC phenotype for one isolate (data not shown). PCR using appropriate primers [15-17] revealed the presence of the extended-spectrum $ß$-lactamase CTX-M15 in 4 isolates, CTX-M-14 in one, and the plasmidic AmpC-type ß-lactamase CMY-2 in a further isolate. Taking into consideration the possibility of reduced carbapenem susceptibility caused by alterations of outer membrane proteins in combination with an ESBL- or an AmpC-type enzyme as decribed previously [18,19], these results offer an explanation for the initial growth of these isolates on the selective medium.

In conclusion, our study testifies the current absence of carbapenemase-producers in healthy people and primary care patients in Switzerland, indicating that carbapenemase-producers have not entered the community in this country. Additional studies should be carried out in future in order to continuously evaluate the dissemination of carbapenemase-producers among enteric bacteria in the population, including screening of patients transferred from hospitals from countries where carbapenemase-producers have been detected. Utmost care should be taken to minimize the impact of the emerging crisis of carbapenem resistant Enterobacteriaceae.

\section{Ethical approval}

The sampling of primary care patients was approved of by the local ethics committee of Zurich and is registered as number KEK-StV-Nr. 54/12.

\section{Consent}

Informed consent was obtained from the patient for the publication of this report and any accompanying images.

Competing interests

The authors declare that they have no competing interests.

\section{Authors' contributions}

$\mathrm{RS}, \mathrm{HH}$ and $\mathrm{MNI}$ conceived the study and $\mathrm{MNI}$ drafted the manuscript. $\mathrm{KZ}$ participated in the design of the study and carried out the microbiological and molecular biological tests. All authors read and approved the final manuscript.

\section{Acknowledgements}

This project was partially funded by the Swiss Federal Office of Public Health. We thank Helga Abgottspon for technical assistance.

Received: 21 March 2013 Accepted: 1 September 2013

Published: 4 September 2013

\section{References}

1. Akova M, Daikos GL, Tzouvelekis $L$, Carmeli Y: Interventional strategies and current clinical experience with carbapenemase-producing Gram-negative bacteria. Clin Microbiol Infect 2012, 18:439-448.

2. Ambler RP, Coulson AF, Frère JM, Ghuysen JM, Joris B, Forsman $M$, Levesque RC, Tiraby G, Waley SG: A standard numbering scheme for the class A beta-lactamases. Biochem J 1991, 276:269.

3. Nordmann P, Naas T, Poirel L: Global spread of Carbapenemaseproducing Enterobacteriaceae. Emerg Infect Dis 2011, 17:1791-1798. 
4. Grundmann H, Livermore DM, Giske CG, Canton R, Rossolini GM, Campos J, Vatopoulos A, Gniadkowski M, Toth A, Pfeifer Y, Jarlier V, Carmeli Y, CNSE Working Group: Carbapenem-non-susceptible Enterobacteriaceae in Europe: conclusions from a meeting of national experts. Euro Surveill 2010, 15(46)

5. Filippini M, Masiero G, Moschetti K: Socioeconomic determinants of regional differences in outpatient antibiotic consumption: evidence from Switzerland. Health Policy 2006, 78:77-92.

6. Plüss-Suard C, Pannatier A, Kronenberg A, Mühlemann K, Zanetti G: Hospital antibiotic consumption in Switzerland: comparison of a multicultural country with Europe. J Hosp Infect 2011, 79:166-171.

7. Poirel L, Lienhard R, Potron A, Malinverni R, Siegrist HH, Nordmann P: Plasmid-mediated carbapenem-hydrolysing $\beta$-lactamase KPC-2 in a Klebsiella pneumoniae isolate from Switzerland. $J$ Antimicrob Chemother 2011, 66:675-676.

8. Babouee B, Widmer AF, Dubuis O, Ciardo D, Droz S, Betsch BY, Garzoni C, Führer U, Battegay M, Frei R, Goldenberger D: Emergence of four cases of KPC-2 and KPC-3-carrying Klebsiella pneumoniae introduced to Switzerland, 2009-10. Euro Surveill 2011, 16(11).

9. Poirel L, Schrenzel J, Cherkaoui A, Bernabeu S, Renzi G, Nordmann P: Molecular analysis of NDM-1-producing enterobacterial isolates from Geneva, Switzerland. J Antimicrob Chemother 2011, 66:1730-1733.

10. Potron A, Schrenzel J, Poirel L, Renzi G, Cherkaoui A, Nordmann P. Emergence of OXA-48-producing Enterobacteriaceae in Switzerland. Int J Antimicrob Agents 2012, 40:563-564.

11. Nüesch-Inderbinen MT, Abgottspon $H$, Zurfluh K, Nüesch HJ, Stephan $R$ Hächler H: Cross-sectional study on fecal carriage of Enterobacteriaceae with resistance to extended-spectrum cephalosporins in primary care patients. Microb Drug Resist. in press, doi:10.1089/mdr.2013.0013.

12. Poirel L, Walsh TR, Cuvillier V, Nordmann P: Multiplex PCR for detection of acquired carbapenemase genes. Diagn Microbiol Infect Dis 2011, 70:119-123.

13. Ellington MJ, Kistler J, Livermore DM, Woodford N: Multiplex PCR for rapid detection of genes encoding acquired metallo- $\beta$-lactamases. J Antimicrob Chemother 2007, 59:321-322.

14. Clinical and Laboratory Standards Institute: Performance standards for antimicrobial susceptibility testing, Twenty-first informational supplement, CLSI document M100-S21 2008. Wayne; 2011.

15. Geser N, Stephan R, Korczak BM, Beutin L, Hächler H: Molecular identification of extended-spectrum- $\beta$-lactamase genes from Enterobacteriaceae isolated from healthy human carriers in Switzerland. Antimicrob Agents Chemother 2012, 56:1609-1612.

16. Briñas L, Moreno MA, Zarazaga M, Porrero C, Sáenz Y, García M, Dominguez $L$, Torres C: Detection of CMY-2, CTX-M-14, and SHV-12 $\beta$-lactamases in Escherichia coli fecal-sample isolates from healthy chickens. Antimicrob Agents Chemother 2003, 47:2056-2058.

17. Endimiani A, Rossano A, Kunz D, Overesch G, Perreten V: First countrywide survey of third-generation cephalosporin-resistant Escherichia coli from broilers, swine, and cattle in Switzerland. Diagn Microbiol Infect Dis 2012, 73:31-38.

18. Lartigue MF, Poirel L, Poyart C, Réglier-Poupet H, Nordmann P: Ertapenem resistance of Escherichia coli. Emerg Infect Dis 2007, 13:315-317.

19. Stapleton PD, Shannon KP, French GL: Carbapenem resistance in Escherichia coli associated with plasmid-determined CMY-4 beta-lactamase production and loss of an outer membrane protein Antimicrob Agents Chemother 1999, 43:1206-1210.

\section{Submit your next manuscript to BioMed Central and take full advantage of:}

- Convenient online submission

- Thorough peer review

- No space constraints or color figure charges

- Immediate publication on acceptance

- Inclusion in PubMed, CAS, Scopus and Google Scholar

- Research which is freely available for redistribution

Submit your manuscript at www.biomedcentral.com/submit
Ciomed Central 